\title{
ESTABLISHING THE EQUIPMENT-METHODICAL SUPPORT FOR DETERMINING THE PROPERTIES OF EXTRACTS OF GRAPE POMACE EXTRACTS PRODUCED IN THE SUBCREATIVE WATER ENVIRONMENT
}

\author{
Valeri Sukmanov \\ Department of technological equipment for food production and commerce \\ Higher Educational Establishment of Ukoopspilka «Poltava University of Economics and Trade» \\ 3 Kovalia str., Poltava, Ukraine, 36014 \\ Sukmanovvaleri@gmail.com \\ Anatoliy Ukrainets \\ National University of Food Technologies \\ 68 Volodymyrska str., Kyiv, Ukraine, 01601 \\ ukrainets@nuft.edu.ua \\ Volodymyr Zavialov \\ Department of Processes and Apparatus of the Food Industry Department \\ National university of food technologies \\ 68 Volodymyrska str., Kyiv, Ukraine, 01601 \\ zavialov@nuft.edu.ua,vlzavialov@gmail.com \\ Marynin Andrii \\ Problem research laboratory \\ National University of Food Technologies \\ 68 Volodymyrska str., Kyiv, Ukraine, 01601 \\ andrii_marynin@ukr.net
}

\begin{abstract}
Research objective: development of a high-pressure reactor for researching the process of extraction of grape pomace by the subcritical water and determining the parameters, providing the maximum yield of various target products - biologically active substances; formation of methodological support for raw material preparation, qualitative and quantitative analysis of extracts, produced by the subcritical extraction. As a result of simulation in the ANSYS system of the stress-strain state of the walls of the reactor chamber and a set of calculation operations, a high-pressure reactor was created that meets the requirements. The formed methodical complex for determining the physicochemical properties of extracts and the content of various biologically active substances included methods for preparing samples and determining the yield of dry extractive substances, evaluation of extraction of polyphenols (tannic-catechol complex), evaluation of extraction of reducing substances, identification furfural and gallic acids, estimation of free organic acids in terms of tartaric acid, evaluation of antioxidant activity of extracts). This methodological complex allows us to estimate the physico-chemical properties of the extracted biologically active substances.
\end{abstract}

Keywords: grape pomace, biologically active substances, extraction, subcritical water, antioxidant activity.

\section{Introduction}

According to the FAOOOH (Food and Agriculture Organization of the United Nations), the world production of grapes is more than 76 million tons per year. The production of grapes in Ukraine in recent years is growing, and in 2016 exceeded 390 thousand tons [1].

As a result of the processing of grapes, up to $20 \%$ of waste grape pomace (GP) is produced, which have a rich polysaccharide complex and contain a considerable amount of phenolic substances and lignin. The pomace consists of 37 ... $39 \%$ (of the total mass) of the grape's skin; $15 \ldots 34 \%$ - from particles of pulp, $1.0 \ldots 3.3 \%$ - from the rests of the crests, $23 \ldots 39 \%$ of the seeds. The moisture content of the pomace depends on the quality of the pressing and varies from 50 to $60 \%$. 
The technological reserve of polyphenol grapes in Ukraine exceeds 500 tons of total polyphenols per year. In this way, the polyphenols of grapes in their native form are mainly flavonoids - poorly soluble in water substances.

Up to $60 \%$ of the mass of dry GP explosives are polysaccharides [2], which are a valuable raw material for the production of biologically active substances (BAS) with high antioxidant properties, including polyphenols, gallic and tartaric acid and its salts, etc. [3].

In the traditional extraction technologies, the target product isn't extracted completely, the processes are time-consuming, the contents of ballast substances is too high, the labor intensity of the process is high, there are losses of the extractant during diffusion and evaporation.

The most effective and innovative method of extracting plant raw materials in the food and pharmaceutical industries is currently the extraction by subcritical water (SCW) [5-7]. SCW - water in a liquid state at a pressure of up to 21,8 in the temperature range between the usual boiling point $\left(100^{\circ} \mathrm{C}\right)$ and the critical temperature $\left(374^{\circ} \mathrm{C}\right)$.

Advantages of using SKW as a solvent: combination of properties of gases at high pressure (low viscosity, high diffusion coefficient) and liquids (high solubility capacity); a combination of negligibly low interfacial tension with low viscosity and a high diffusion coefficient; high sensitivity of solvent ability to change pressure or temperature; simplicity of separation by SCW and dissolved substances when the pressure is released; SCW penetrates into porous structures more easily in comparison with traditionally used liquid solvents.

The main problem is the full use of the GP namely their high humidity and the need for their speedy processing to exclude the development of molds and prevent the spoilage. GP begins to deteriorate after 2-3 days and with high humidity (85-90\%) and elevated temperatures $\left(25 \ldots 40{ }^{\circ} \mathrm{C}\right)$, the storage period is $8-12$ hours.

The chemical composition of the processed raw materials depends significantly on the soil-climatic conditions and varietal characteristics of the grapes, as evidenced by the numerous data have given in the literature on the biochemical composition of the GP [3]. These circumstances lead to the need to study the extraction processes of the GP products from those varieties of grapes that are common in the regions of the location of processing enterprises, subject to modernization.

Extraction of SCW provides more complete extraction, there is a selectivity of the process in relation to different target products and the ecological purity of the extract obtained $[4-6,9]$.

The effect of the use of flavonoids is mainly due to the antioxidant activity of these compounds. At the same time, antioxidant activity is considered as a function not of individual groups of flavonoids, but of all polyphenols, including tannins (tannic-catechol complex). Therefore, if flavonoids are considered as an antioxidant additive, then it is advisable not to separate them from tannins, but to use them together with the latter.

The recovered polyphenols have a fairly wide range of bio-physico-chemical properties, but to date there is no single of extraction protocol that could be considered optimal for all samples studied [10].

In various grades of grapes the content of BAS and their quantity is different. Based on this, the research into the extraction of BAS from grape and GP is focused on the determination of rational process parameters exclusively for the raw material being studied. Thus, it should be noted that the process of extraction by SCW from the GP of the table grape Moldova, which is widespread in Ukraine, the Republic of Moldova, in a number of European countries, has not been investigated at present. The conduct of such studies is limited by the lack of specific equipment, providing the process of extraction by SCW and a complex of methodological support for the physicochemical analysis of extracts obtained for the presence of BAS.

Research objective:

- the development of a high-pressure reactor to conduct the research on the extraction process of GP by SCW and definition of parameters that providing the maximum yield of various target products - BAS;

- formation of methodological support for raw material preparation, qualitative and quantitative analysis of extracts produced by subcritical extraction. 


\section{Materials and Methods}

Creation of experimental equipment. As a result of the analysis of the existing designs of high-pressure reactors of the world's leading manufacturers, the initial requirements for the equipment being created were formulated. When it was created, first of all, the stress-strain state of the working chamber from internal pressure, temperature, cyclic loads, fatigue was studied, and boundary conditions were analyzed, etc.

The external working surface of the working chamber of the high-pressure reactor is connected to TENs with a temperature of $673 \mathrm{~K}$, the internal one is at room temperature. An existing temperature drop leads to the appearance of thermoelastic stresses. Existing analytical solutions that the temperature change for a thick-walled cylinder obeys a linear dependence, in this case are not applicable, because the temperature distribution between the external and internal surfaces of the structure is not linear.

One of the modern methods for calculating the strength is the method of finite elements and it was implemented in the software product ANSYS. In the task set, the following were taken into account: real geometry of reactor design; dependence of the coefficients of thermal conductivity, linear expansion, Young's modulus and Poisson's coefficient ratio on temperature; non-linear temperature variation between the outer and inner surfaces of the walls of the autoclave; large (finite) deformations are allowed.

The problem was solved within the framework of the theory of elasticity by the method of physical media. As a result of the symmetry, an axisymmetric formulation is used to solve the problem. When constructing the finite element model, 12100 elements were used. Discretization was produced using a solid 8-node thermal element PLANE77 to solve a thermal problem and a compatible with it structural PLANE82 for perform the structural analysis. Both elements make it possible to solve the problem in an axisymmetric formulation, admit more than one form, which makes it possible to construct a predominantly ordered rectangular grid. In solving this problem, the thermal problem was solved at the first stage. We constructed a geometric and finite element model of the reactor working chamber. Boundary conditions for the thermal problem: the temperature on the inner surface is $293 \mathrm{~K}$, on the outer surface is $673 \mathrm{~K}$. As a result of the solution has got the temperature distribution in the autoclave housing. The dependence of the temperature on the radius is shown in Fig. 1.

At the second stage, the structural problem was solved for which the structural boundary conditions were set, the thermal file by physics was read and they were jointly solved.

In Fig. 2 shows the diagrams of radial and equivalent Mises stresses in the wall of the working chamber of a high-pressure reactor, obtained as a result of modeling.

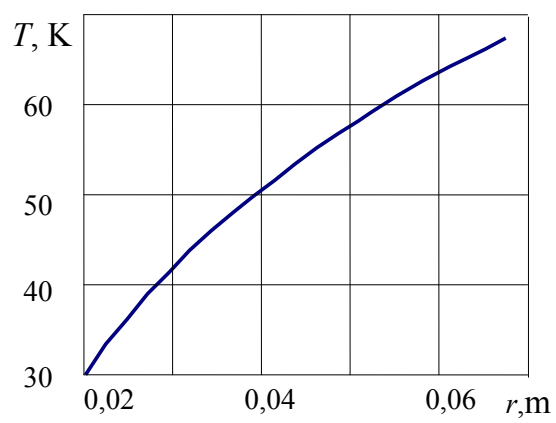

Fig. 1. Change in temperature along the thickness of the wall of the working chamber

Fig. 3 shows the dependence of radial stresses $\sigma_{\mathrm{r}}$ (curve 1) and equivalent $\sigma_{\text {eq }}$ (curve 2) on the radius of the working chamber $r$. The resultant stress is far from the ultimate strength of the material.

Comparison of the results of stress calculations in the wall of the working chamber of a high-pressure reactor (Fig. 4) confirmed the reliability of the results obtained and was used in designing both, the body of the working chamber and directly the reactor itself, the appearance of which is shown in Fig. 5. 


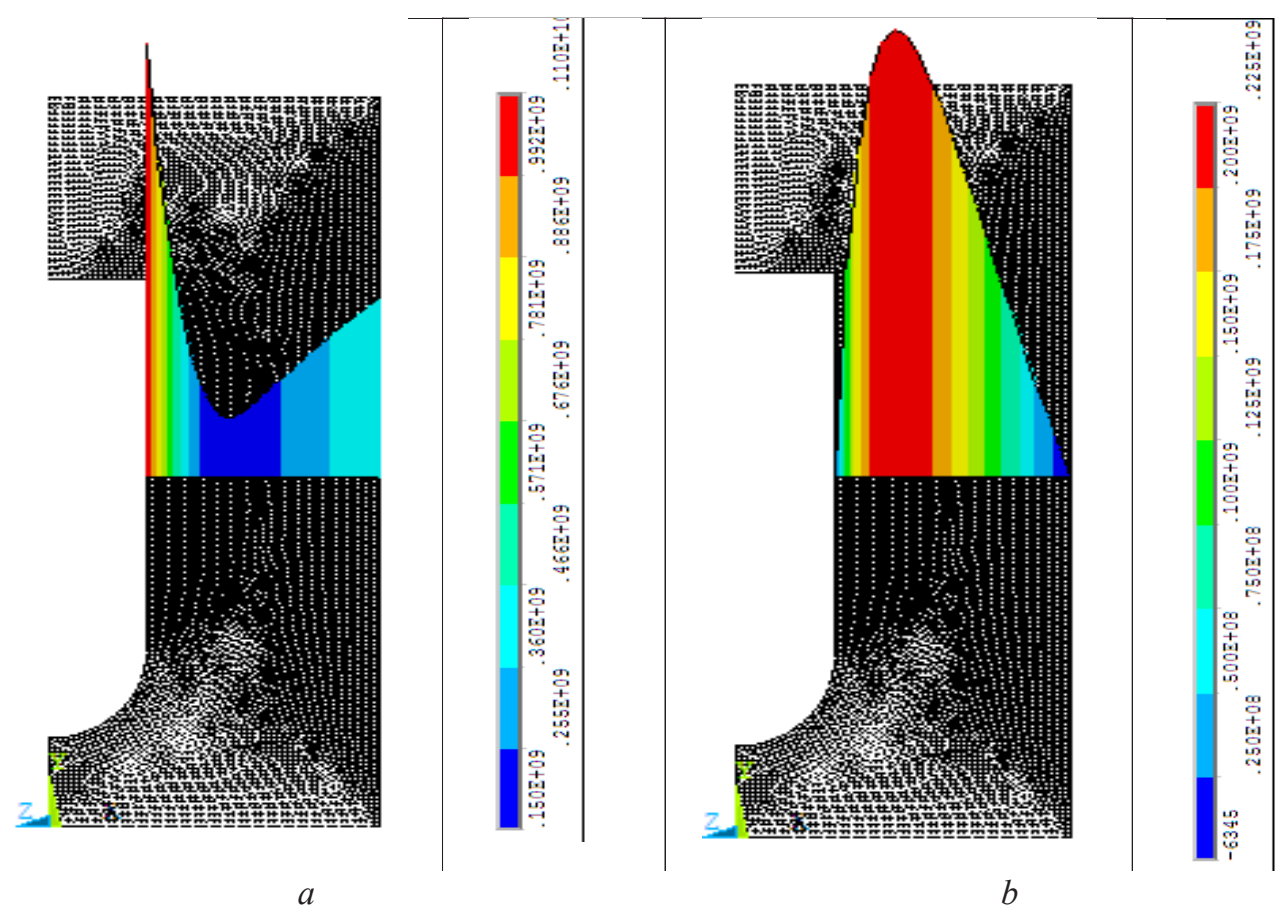

Fig. 2. Diagram of stresses in the wall of the working chamber of a high-pressure reactor: $a$ - radial stresses; $b$ - equivalent Mises stresses

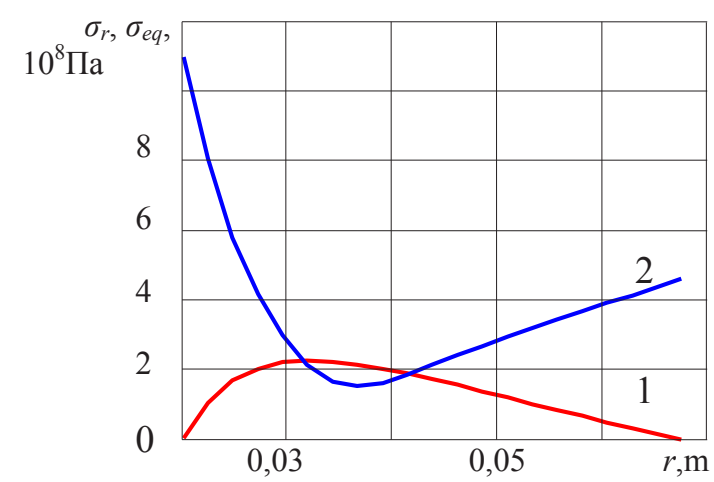

Fig. 3. Dependence of stresses on the radius of the reactor's working chamber $r$ :

1 - radial stresses $\sigma_{\mathrm{r}} ; 2$ - equivalent stresses $\sigma_{\mathrm{eq}}$

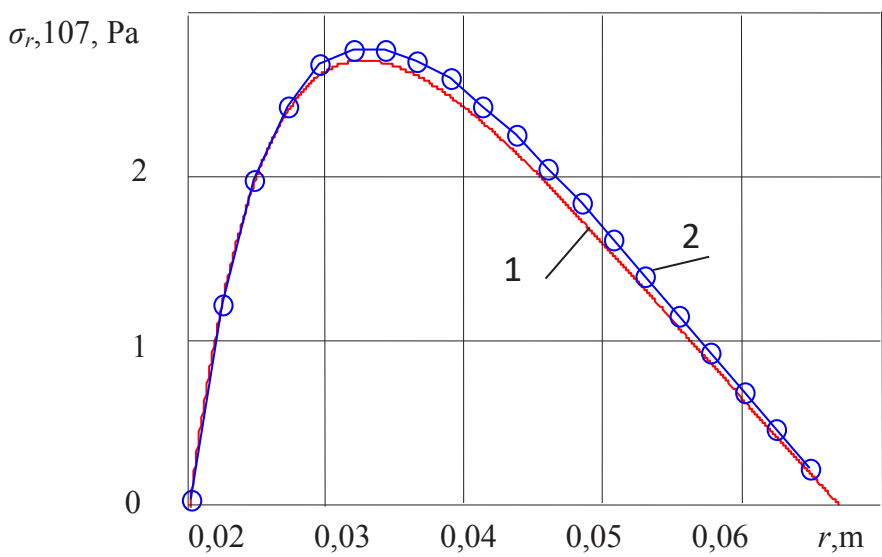

Fig. 4. Results of calculation of radial stresses $\sigma_{\mathrm{r}}$ : curve 1 - by analytical methods, curve 2 - by numerical calculation in ANSYS 


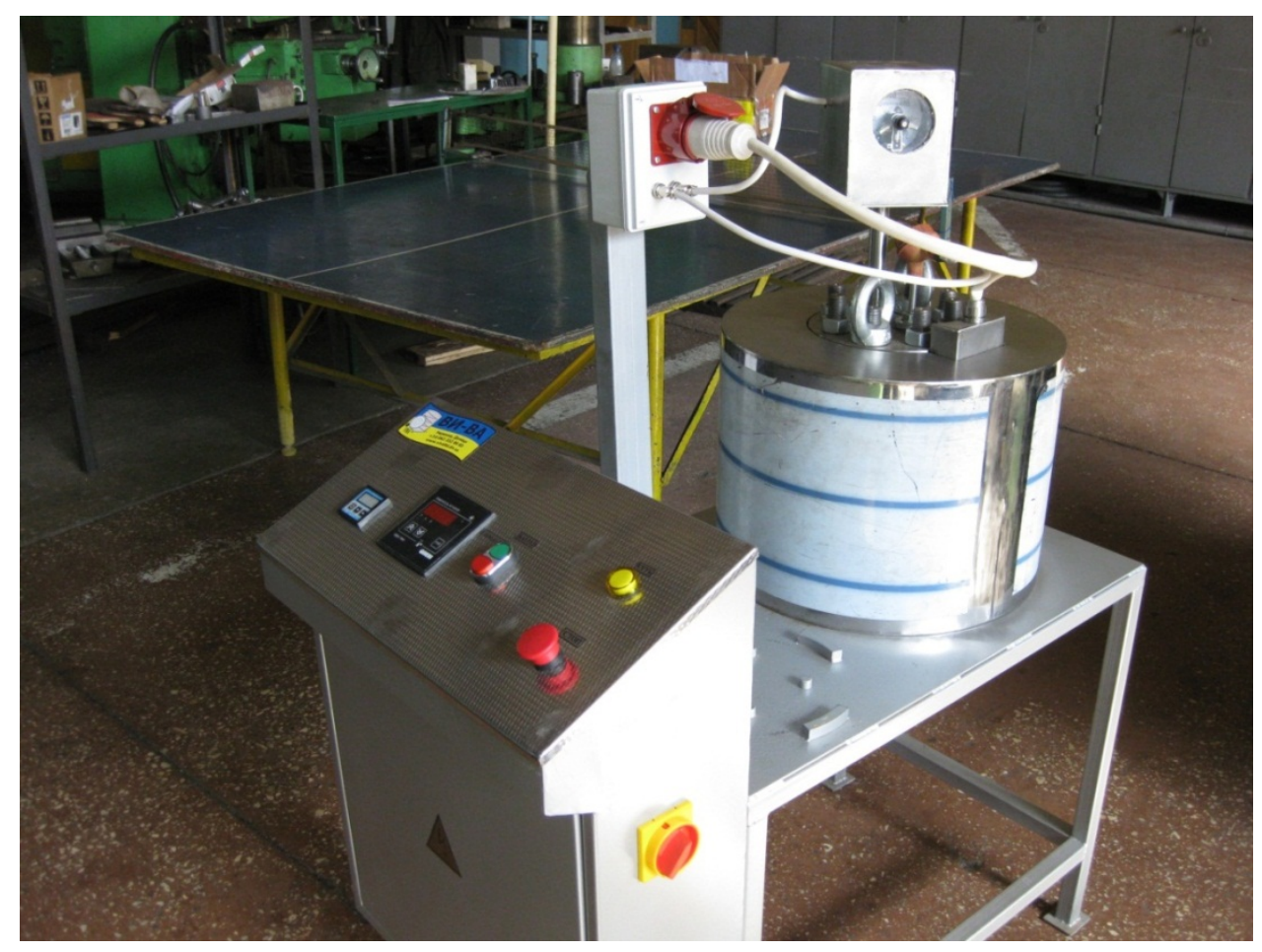

Fig. 5. General view of a high-pressure reactor

The main technical and operational characteristics of the high-pressure reactor: the nominal volume of the working chamber is 0.68 liters, the accuracy of recording the temperature is $\pm 0.5^{\circ} \mathrm{C}$, the sensitivity of the pressure sensor is $\pm 1 \mathrm{MPa}$, the maximum pressure at room temperature is $40 \mathrm{MPa}$, the maximum temperature in the working chamber at an ambient room temperature of $400{ }^{\circ} \mathrm{C}$, the calculated number of loading cycles at pressures up to $40 \mathrm{MPa}$ - not less than 500 cycles [11].

Definition of the field of experimentation. The range of variation of technological process parameters: the ratio of raw materials and extractant (water) with hydro ratio $-1: 5$ and 1:10. The temperature was varied from 100 to $160^{\circ} \mathrm{C}$ with a step of $10^{\circ} \mathrm{C}$ and was maintained with a regulator with an accuracy of $\pm 1^{\circ} \mathrm{C}$. The holding time is $30 \mathrm{~min}, 60 \mathrm{~min}$ and $90 \mathrm{~min}$. The repetition of the experiments at each point was triple. The time was calculated after reaching the set temperature.

The pressure level $(\mathrm{P})$ equals $12 \mathrm{MPa}$, which provides subcritical conditions and a high yield of the extracted substance. It was established based on the thermodynamic properties of water described by the differential equations of thermodynamics of the International System of Equations of 1997 (Formulations IF-97). These equations describe the properties of water in the sub- and supercritical fields. The subcritical field is described by fundamental equations for the Gibbs energy [12].

Method of obtaining dry GP. Drying of the original pomace at $75 \pm 2{ }^{\circ} \mathrm{C}$ to constant weight was carried out in porcelain bowls placed in a drying cabinet ТРЦ02ТП-1. The residual moisture of the pomace after drying was 4-7 (\% abs.). The resulting agglomerates were crushed to a fraction passing through a $3 \mathrm{~mm}$ sieve. Samples in the form of powder were stored in a package that provides protection from the moisture of the environment at room temperature in a dark place.

Method of preparation of samples and determination of the yield of dry extractive substances $(D S)$.

The quantitative of moisture content was calculated by the formula:

$$
\mathrm{u}=\frac{\Delta \mathrm{m}}{\mathrm{m}_{\text {d.s. }}} \cdot 100 \% \text {, }
$$

where $\Delta \mathrm{m}$ - mass of remote moisture, $\mathrm{g} ; \mathrm{m}_{\mathrm{d} . \mathrm{s} .}$ - product massage after drying cabin, $\mathrm{g}$. 
The calculation of humidity was carried out according to the formulas:

$$
\mathrm{C}=\frac{\Delta \mathrm{m}}{\mathrm{m}_{\mathrm{h} . \mathrm{s} .}} \cdot 100 \%,
$$

where $\Delta \mathrm{m}$ - mass of remote moisture, $\mathrm{g} ; \mathrm{m}_{\mathrm{h} . \mathrm{s} .}$ - product massage before drying cabin, $\mathrm{g}$.

To prepare the sample, the GP was weighed, recalculated to an absolutely dry substance matter and, in accordance with the accepted hydro ratio, was poured with a portion of degassed distilled water. The sample was kept then under continuous stirring for 45 minutes. Thus, the subsequent extraction process was not affected by the diffusion of water deep into the dry plant material, which would be limited the extraction process in the initial period of time. The filtration of the extract was carried out on a Buchner funnel under a vacuum of $\sim 0,5 \mathrm{~atm}$. A water pump Pedrollo PKm 60 was used to create the necessary water pressure in a water-jet vacuum pump. The filtration was carried out first on a cotton cloth (cotton cloth "belting") thereafter the extract is further filtered through a "blue tape". The yield of the dry extract was determined by evaporating the exact volume of the extract $(50 \mathrm{ml})$ at $105{ }^{\circ} \mathrm{C}$ under vacuum on a rotary evaporator IR-1M with a temperature regulator ERA-M to constant weight.

Method for evaluation of polyphenols extraction (tannic-catechin complex). The total content of polyphenol compounds of polyphenols (tannic-catechin complex) (Ph) was determined in terms of gallic acid by the method of Folin-Ciocalteu [13].

Total amount of polyphenol compounds in $\%$ based on gallic acid was calculated according to the formula:

$$
\mathrm{X}=\frac{\mathrm{D} \cdot \mathrm{m}_{0} \cdot 25 \cdot 1 \cdot 100 \cdot 100 \cdot 100}{\mathrm{D}_{0} \cdot \mathrm{m} \cdot \mathrm{a} \cdot 100 \cdot 100 \cdot(100-\mathrm{w})}
$$

where D - optical density of test solution; $\mathrm{D}_{0}$ - optical density of standard solution of gallic acid; $\mathrm{m}$ - mass of extracted cake, $\mathrm{g} ; \mathrm{m}_{0}$ - mass in grams of gallic acid; a - aliquot solution in $\mathrm{ml} ; \mathrm{w}-$ loss on drying of the extract in percentage.

Method for evaluation of extraction of reducing substances $(R S)$. Determination of the yield of reducing substances (RS) was carried out using Feling's reagent [14]. Subsequently, the difference in the flow rates of $\mathrm{Na}_{2} \mathrm{~S}_{2} \mathrm{O}_{3}$ solution in control and working experiments was found using an empirical table. The amount of sugar in the sample of the extract taken for analysis was determined. When analyzing the extract of GP, the recalculation was carried out on glucose and after determination, the conversion to the yield of reducing substances from dry GP was performed.

Method of furfural identification. To identify furfural from the extraction products, the nuclear magnetic resonance (NMR) method was used. The investigations were carried out on a multifunction spectrometer of 'Bruker' Avance II $400 \mathrm{MHz}: 50 \mathrm{ml}$ of the substance (furfural) were placed in an ampoule with a solvent (deuterated water or deuterated chloroform). The sample was placed in a strong homogeneous magnetic field $\mathrm{H}_{\mathrm{o}}$ and acted on it by radiation with a frequency v: ${ }^{1} \mathrm{H}-400 \mathrm{MHz},{ }^{13} \mathrm{C}-100 \mathrm{MHz}$ at temperature $293 \mathrm{~K}$. Under these conditions, transitions from one nuclear magnetic level to another occur, which causes the phenomenon of nuclear magnetic resonance, i. e., the absorption of radio-frequency radiation. Absolute chemical shift (signal shift relative to the signal of an unshielded proton) can't be experimentally determined, so the chemical shift is measured with respect to the signal of the reference substance. Chemical shifts (ppm) of the model furfural and obtained extract were compared with chloroform of $\mathrm{CDCl}_{3}$ as the model.

Method of gallic acid identification. For the production of tannins, when extracted by SCW, $25 \mathrm{~g}$ of powdered GP was subjected to extraction at $110^{\circ} \mathrm{C}$, the hydro ratio $1: 10$, and a holding time of $30 \mathrm{~min}$. The resulting extract was transferred to a separatory funnel. Dissolve $10 \mathrm{ml}$ of sodium chloride in it and extract first $30 \mathrm{ml}$, and then $50 \mathrm{ml}$ with a mixture of butyl acetate and butyl alcohol (3:1). The resulting solution of tannins in organic solvents was poured into a flask Wurtz, an equal volume of distilled water was added and distilled under vacuum in a boiling water bath. The resulting viscous mass was transferred to a porcelain bowl. To dry the resulting tannin, a porcelain 
bowl was placed in a vacuum desiccator and a powder (tannin) of gray color with astringent taste was obtained.

Hydrolyzable tannins are derivatives of gallic acid, which not being a flavonoid, exhibits high antioxidant activity. Gallic acid can be obtained in pure form by the hydrolysis of tannins.

For gallic acid obtaining according to, $4 \mathrm{~g}$ of tannin and $40 \mathrm{ml}$ of 50 percent sulfuric acid were heated on a boiling water bath for 10 hours. The cooled hydrolyzate was transferred to a separatory funnel and extracted 3-4 times with small portions of ether. The ether extract was dried and calcined by sodium sulfate, ether was distilled off. The residue was recrystallized from water.

Gallic acid was identified by NMR: $50 \mathrm{ml}$ of the substance (gallic acid) was placed in an ampoule with a solvent (deuterated water or deuterated chloroform). Recording parameters of spectra: chemical shifts (ppm) are given for $\mathrm{D}_{2} \mathrm{O},{ }^{1} \mathrm{H}-400 \mathrm{MHz},{ }^{13} \mathrm{C}-100 \mathrm{MHz}$, temperature $293 \mathrm{~K}$.

Method for evaluation the content of free organic acids in terms of tartaric acid. The determination of the titratable acidity (A) was carried out by alkylmetric titration with phenolphthalein as an indicator [15].

The content of free organic acids in terms of tartaric acid in absolutely dry raw materials in percent $(\mathrm{X})$ was calculated according to the formula [16]:

$$
\mathrm{X}=\frac{\mathrm{V} \cdot \mathrm{K} \cdot 0,0075 \cdot \mathrm{V}_{\text {извлл }} \cdot 100}{\mathrm{~m} \cdot \mathrm{V}_{\mathrm{a}}} \cdot \frac{100}{(100-\mathrm{W})},
$$

where 0.0075 is the amount of tartaric acid corresponding to $1 \mathrm{ml}$ of sodium hydroxide solution $(0,1 \mathrm{~mol} / \mathrm{l}), \mathrm{g} ; \mathrm{V}$ - the volume of sodium hydroxide solution $(0,1 \mathrm{~mol} / \mathrm{l})$, which went to titration, $\mathrm{ml}$; $\mathrm{K}$ - the coefficient of bringing the concentration of the alkali solution exactly to $0,1 \mathrm{n} ; \mathrm{V}_{\text {extr }}-$ volume of extract, $\mathrm{ml} ; \mathrm{V}_{\mathrm{a}}$-volume of extract sample taken for titration, $\mathrm{ml} ; m$ - mass of sample, $\mathrm{g}$; $W-$ loss in mass when drying raw materials, $\% \cdot \frac{100}{(100-\mathrm{W})}-$ conversion factor for absolutely dry raw material.

Evaluation of the extracts antioxidant activity. The antioxidant activity of the studied extracts and the kinetics of inhibition of free radicals were studied by the spectrophotometric method DPPH. For the experiment, $3,9 \mathrm{ml}$ of a solution of DPPH with a concentration of $60 \mu \mathrm{M}$ and $0,1 \mathrm{ml}$ of the sample of the extract to be analyzed are introduced into the quartz cuvette. Absorption is read on a spectrophotometer for 30 minutes, after every minute. To determine the free radical concentration, a calibration schedule was constructed.

The antioxidant activity of the extract was determined by the formula:

$$
\mathrm{AA} \%=\frac{[\mathrm{DPPH}]_{0}-[\mathrm{DPPH}]_{\mathrm{t}}}{[\mathrm{DPPH}]_{0}} \cdot 100
$$

$[\mathrm{DPPH}]_{0}-$ concentration of radical DPPH in set moment of time $\mathrm{t}=0 \mathrm{sec} ;[\mathrm{DPPH}]_{\mathrm{t}}-$ concentration of radical DPPH determined on spectrophotometer after $30 \mathrm{sec}$.

\section{Conclusions}

As a result of the completed complex of studies and design and calculation work, a high-pressure reactor was created to conduct research on the extraction of GP by SCW and to determine the parameters that ensure the maximum yield of various target products - BAS. The main technical and operational characteristics of the high-pressure reactor: the nominal volume of the working chamber is 0,681 , accuracy of temperature recording, $\pm 0,5{ }^{\circ} \mathrm{C}$, sensitivity of the pressure sensor $- \pm 1 \mathrm{MPa}$, maximum pressure at room temperature, $40 \mathrm{MPa}$, the maximum temperature in the working chamber at an ambient room temperature of $400{ }^{\circ} \mathrm{C}$, the estimated number of loading cycles at a pressure of up to $40 \mathrm{MPa}$ is not less than 500 cycles.

Areas of experimentation are determined and methodical support for raw material preparation is formed (a technique for obtaining dry GP), qualitative and quantitative analysis of extracts, 
produced by subcritical extraction (a technique for preparing samples and determining the yield of dry extractive substances, a method for evaluating the recovery of polyphenols (tannic-catechol complex), a technique for estimating the extraction of reducing substances, a technique for identifying furfural and gallicacids, method for estimating the content of free organic acids in terms of tartaric acid, a technique for evaluating the antioxidant activity of extracts. This methodological complex makes it possible to comprehensively evaluate the physicochemical properties of the extracted BAS.

\section{References}

[1] International Organization of Vine and Wine (2016). Statistical Report on World Vitiviniculture. Paris. Available at: http://www.oiv.int/public/medias/5029/world-vitiviniculture-situation-2016.pdf

[2] Issa, G., Patti, A. F., Smernik, R., Wilkinson, K. (2009). Chemical composition of composted grape marc. Water Science \& Technology, 60 (5), 1265-1271. doi: 10.2166/wst.2009.564

[3] Wang, X., Tong, H., Chen, F., Gangemi, J. D. (2010). Chemical characterization and antioxidant evaluation of muscadine grape pomace extract. Food Chemistry, 123 (4), 1156-1162. doi: 10.1016/j.foodchem.2010.05.080

[4] Xia, E.-Q., Deng, G.-F., Guo, Y.-J., Li, H.-B. (2010). Biological Activities of Polyphenols from Grapes. International Journal of Molecular Sciences, 11(2), 622-646. doi:10.3390/ijms11020622

[5] Plaza, M., Turner, C. (2015). Pressurized hot water extraction of bioactives. Trends in Analytical Chemistry, 71, 39-54. doi: 10.1016/j.trac.2015.02.022.

[6] Zakaria, S. M., Kamal, S. M. M. (2015). Subcritical Water Extraction of Bioactive Compounds from Plants and Algae: Applications in Pharmaceutical and Food Ingredients. Food Engineering Reviews, 8 (1), 23-34. doi: 10.1007/s12393-015-9119-x

[7] Liang, X., Fan, Q. (2013). Application of Sub-Critical Water Extraction in Pharmaceutical Industry. Journal of Materials Science and Chemical Engineering, 1 (5), 1-6. doi: 10.4236/msce.2013.15001

[8] Bondakova (Krivchenkova), M. V., Klyishinskaya, E. V., Butova, S. N. (2012). Sovershenstvovanie sposobov polucheniya ekstrakta vinograda s tselyu ego dalneyshego ispolzovaniya pri proizvodstve kosmeticheskih izdeliy. Novyie himiko-farmatsevticheskie tehnologii. Moscow: RHTU im. D. I. Mendeleeva, 154-157.

[9] Rajha, H. N., Darra, N. E., Hobaika, Z., Boussetta, N., Vorobiev, E., Maroun, R. G., Louka, N. (2014). Extraction of Total Phenolic Compounds, Flavonoids, Anthocyanins and Tannins from Grape Byproducts by Response Surface Methodology. Influence of Solid-Liquid Ratio, Particle Size, Time, Temperature and Solvent Mixtures on the Optimization Process. Food and Nutrition Sciences, 05 (04), 397-409. doi: 10.4236/fns.2014.54048

[10] Escribano-Bailon, M., Santos-Buelga, C.; Santos-Buelga, C., Williamson, G. (Eds.) (2003). Polyphenol extraction from foods. Methods in polyphenol analysis. Cambridge: The Royal Society of Chemistry, 1-16.

[11] Sukmanov, V. O., Petrova, Yu. M., Lahovskyi, I. O. (2015). Apparaturnoe oformlenye protsessa ekstrahyrovanyia byolohychesky aktyvnikh veshchestv yz vizhymok vynohrada $\mathrm{v}$ srede subkrytycheskoi vody. Aktualni problemy ta perspektyvy rozvytku kharchovykh vyrobnytstv, hotelno-restorannoho ta turystychnoho biznesu. Poltava: PUET, 276-277.

[12] Alexandrov, A. (1998). Management system IAPWS-IF97 for calculating of thermodynamic properties of water and steam for industrial calculations. Additional equations. Fittings, 10, 64-72.

[13] Xia, E.-Q., Deng, G.-F., Guo, Y.-J., Li, H.-B. (2010). Biological Activities of Polyphenols from Grapes. International Journal of Molecular Sciences, 11 (2), 622-646. doi: 10.3390/ijms11020622

[14] Veshnyakov, V. A., Habarov, Yu. G., Kamakina, N. D. (2008). Sravnenie metodov opredeleniya redutsiruyuschih veschestv: metod Bertrana, ebuliostaticheskiy i fotometricheskiy metodyi. Himiya rastitelnogo syirya, 4, 47-50.

[15] Ryizhova, G. L., Matasova, S. A., Bashurov, S. G. (1997). Poluchenie suhogo ekstrakta iz plodov ryabinyi sibirskoy i izuchenie ego himicheskogo sostava. Himiya rastitelnogo syirya, 2, 37-41.

[16] Issa, G. (Jason), Patti, A. F., Issa, G. (Jason), Smernik, R., Wilkinson, K. (2009). Chemical composition of composted grape marc. Water Science \& Technology, 60 (5), 1265. doi: 10.2166/wst.2009.564 